\title{
Welding Quality Engineering Using the Design of Experiment Method (Taguchi's Method)
}

\section{Rekayasa Kualitas Hasil Las dengan Menggunakan Metode Design of Experiment (Taguchi's Method)}

\author{
Anis Siti Nurrohkayati ${ }^{1}$, Dede Zulrahman ${ }^{2}$, Sabaruddin Syach $^{3}$, Muhammad Khairul ${ }^{4}$ \\ \{asn826@umkt.ac.id ${ }^{1}$, dedezulrahman@gmail.com ${ }^{2}$, sabaruddinsyach@gmail.com ${ }^{3}$ \}
}

Program Studi Teknik Mesin, Universitas Muhammadiyah Kalimantan Timur

\begin{abstract}
The technology in modern era and rapid construction sector has made welding an important role in the field of metal engineering and repair. Therefore, the technology in the construction sector, especially in the engineering sector, requires a welding element. Welding is used to combine with metal. Making this connection requires high skill for welder in order to obtain a good quality connection. The aim of this study was to determine the quality of a good welding result using the design of experiment method by looking at the control factor of the electrode, welding amperage, welding method, plate thickness, and welding speed. In addition to control factors, there are also use noise factors such as skill, cleanliness of work pieces, and distance between work pieces. The results of the experiments are based on weld defect criteria and the DOE method with ANOVA calculations, the best welding results are in trial no 7 with an average value of 0.22 . Meanwhile, the results of the experiment with welding defects is trial experiment no 2 with a value of 0.64. The factors that influence the quality of the welds are plate thickness, welding amperage, electrodes, and welding method. Meanwhile, the welding speed factor is a factor that does not significantly affect the weld quality.
\end{abstract}

Keywords - design of experiment; control factor; noise factor; welding

\begin{abstract}
Abstrak. Pertumbuhan dan pengembangan teknologi di bidang konstruksi yang semakin maju dan sangat pesat membuat pengelasan berperan penting dalam bidang rekayasa dan reparasi logam. Oleh sebab itu, pengembangan teknologi di bidang konstruksi khususnya di bidang rancang bangun membutuhkan unsur pengelasan. Pengelasan disini digunakan untuk menyambung logam. Pembuatan sambungan ini memerlukan ketrampilan yang tinggi bagi pengelasnya agar diperoleh sambungan dengan kualitas baik. Pada penelitian ini bertujuan untuk mengetahui kualitas hasil las yang baik dengan menggunakan metode design of experiment dengan melihat control factor elektroda, ampere las, metode pengelasan, tebal plat, dan kecepatan pengelasaan. Selain control faktor, juga terdapat noise faktor yang digunakan yaitu keahlian, kebersihan benda kerja, dan jarak antar benda kerja. Hasil penilaian berdasarkan kriteria cacat las dan metode DOE dengan perhitungan ANOVA, hasil las paling baik yaitu pada trial no 7 dengan nilai rata-rata 0,22. Sedangkan, hasil eksperimen dengan cacat las yaitu eksperimen trial no 2 dengan nilai 0,64. Faktor yang mempengaruhi kualitas hasil las secara berurut yaitu tebal plat, ampere las, elektroda, dan metode pengelasan. Sedangkan, faktor kecepatan pengelasan merupakan faktor yang secara sognifikan tidak mempengaruhi kualitas las.
\end{abstract}

Kata Kunci - design of experiment; rekayasa; kontrol factor; noise factor; pengelasan

\section{PENDAHULUAN}

Pengelasan adalah proses pembuatan yang biasanya digunakan untuk menggabungkan dua bagian logam menjadi satu. Proses ini dilakukan dengan melebur kedua benda kerja dan menambahkan bahan pengisi [1]. Pengelasan telah memainkan peran penting dalam kemampuan manusia untuk membuat dan membangun sejak Zaman Perunggu. Optimasi pengelasan dari berbagai macam kondisi variabel yang muncul dapat dilakukan dengan eksperimen percobaan menggunakan metode Taguchi [2].

Metode taguchi dalam bidang teknik bertujuan untuk memperbaiki kualitas produk dan proses, serta menekan biaya dan resources seminimal mungkin [3]. Saat ini, tetap menjadi aspek penting dari fabrikasi dan manufaktur logam. Dalam penelitian ini digunakan teknik DOE, overall evaluation criteria (OEC), dan ANOVA untuk menganalisis hasil. DOE adalah salah satu dari banyak teknik yang digunakan dalam praktik peningkatan kualitas. Metode Taguchi ditemukan oleh R.A Fisher di Inggris pada tahun 90 [4]. Fisher ingin mengetahui seberapa banyak hujan, sinar matahari, pupuk, dan air menghasilkan panen terbaik.

Strategi eksperimental di mana efek dari banyak faktor dipelajari secara bersamaan dengan menjalankan tes pada berbagai tingkat faktor. Pengaruh relatif dari faktor dan interaksi, serta tingkat kepercayaan atas perkiraan kinerja pada kondisi optimal dan efek utama, dan signifikansi pengaruh faktor dan interaksi [5]. Hasil ANOVA inner array (control factor) dan S/N-ratio digunakan untuk menganalisis faktor mana yang mempengaruhi kualitas pengelasan. Dalam perhitungan ANOVA, Taguchi menerapkan pooling-up factor untuk mengabaikan kontribusi faktor yang tidak 
signifikan [6]. Faktor penyatuan adalah penggabungan antara sejumlah kecil kotak dengan kesalahan, yang disebut kumpulan kesalahan. Taguchi merekomendasikan untuk melakukan pooling sampai tingkat error pooled mendekati atau sama dengan 0,5 dari total DOF [7].

Pada penelitian ini memiliki tujuan utama percobaan yaitu untuk menentukan kualitas las, untuk mengetahui faktor-faktor apa saja yang mempengaruhi kualitas hasil pengelasan, untuk mengidentifikasi faktor-faktor utama yang berpengaruh signifikan terhadap kualitas terbaik. Pada setiap jenis pengelasan terdapat banyak jenis elektroda yang digunakan.

Pengelasan dalam eksperimen ini dilakukan dengan metode SMAW [8]. Pengelasan dilakukan menggunakan kawat elektroda yang dibungkus dengan fluks. Panas dari busur akan membuat logam induk dan ujung elektroda tersebut mencair dan membentuk butir-butir yang terbawa oleh arus listrik yang terjadi selama proses pengelasan. Panas dari busur akan membuat logam induk dan ujung elektroda tersebut mencair dan membentuk butir-butir yang terbawa oleh arus listrik yang terjadi selama proses pengelasan. Arus listrik sangat berpengaruh pada butir hasil pengelasan, jika arus listrik tinggi maka butir yang dihasilkan akan halus, sedangkan jika arus listrik rendah maka butir yang dihasilkan dalam pengelasan akan lebih kasar. Cacat pada sambungan las dinilai dengan menggunakan spotcheck.

\section{METODE}

Pada penelitian ini menggunakan metode Design of Experiments (DOE). Metode DOE merupakan metode Taguchi yang digunakan untuk merekayasa atau meningkatkan kualitas suatu hasil produk [9]. Metode DOE menggunakan pengulangan eksperimen untuk melihat faktor-faktor apa saja yang sangat berpengaruh terhadap suatu hasil pengelasan. Control factors and Noise factors adalah faktor-faktor yang digunakan untuk merekayasa suatu kualitas produk. Selanutnya, hasil dari pengulangan eksperimen dihitung dan dianalisa dengan menggunakan ANOVA (analisis of variance). Perhitungan dan analisis (ANOVA) akan menghasilkan nilai faktor dan interaksi faktor apa yang paling berpengaruh pada kualitas hasil pengelasan. Selain itu, ANOVA juga akan menghitung tingkat signifikansi dari pengaruh faktor dan interaksi faktor yang digunakan [10], [6].

Pada penelitian ini digunakan control dan noise faktor yang diberikan pada Tabel 1 dan tabel 2. Control factor merupakan faktor-faktor yang berpengaruh secara langsung terhadap kualitas las. Noise factor adalah faktor yang tidak langsung mempengaruhi kualitas dari hasil pengelasan. Control dan noise factor dibedakan menjadi 2 level. Selanjutnya, ekseperimen dilakukan dengan menggunakan L8 OA (outer and inner array) [9]. Orthogonal array merupakan tabel kombinasi level yang digunakan untuk melakukan eksperimen. Berdasarkan dengan tabel L8, pada penelitian ini dilakukan 8 kali pengulangan eksperimen.

Tabel 1. Control Factors

\begin{tabular}{lll}
\hline \multicolumn{3}{c}{ Control Factors } \\
\hline \multirow{2}{*}{ Factor } & \multicolumn{2}{c}{ Level } \\
\cline { 2 - 3 } & 1 & 2 \\
\hline A-Elektroda & RB-28 & RD-460 \\
\hline B-Ampere Las & 40 & 20 \\
\hline C-Metode Pengelasan & Spiral & Zig-zag \\
\hline D-Tebal Plat & 4 mm & 2 mm \\
\hline E-Kecepatan Pengelasan & Cepat & Lambat \\
\hline
\end{tabular}

Tabel 2. Noise Factors

\begin{tabular}{|c|c|c|}
\hline \multicolumn{3}{|c|}{ Noise Factors } \\
\hline \multirow{2}{*}{ Factor } & \multicolumn{2}{|r|}{ Level } \\
\hline & 1 & 2 \\
\hline X-Keahlian & Ahli & Tidak \\
\hline $\begin{array}{l}\text { Y-Kebersihan } \\
\text { Kerja }\end{array}$ & Bersih & Tidak Bersih (ada kerak) \\
\hline Z-Jarak antar benda kerja & $0 \mathrm{~mm}$ & $2 \mathrm{~mm}$ \\
\hline
\end{tabular}

Penilaian hasil las diambil berdasarkan pada referensi dimana terdapat beberapa cacat pada hasil las [11]. Pada penelitian ini kriteria hasil pengelasan diberikan pada Table 3 berikut. Penilaian hasil las dilakukan dengan mengisi 
Procedia of Engineering and Life Science Vol.1 No. 1 March 2021

Seminar Nasional \& Call for Paper Fakultas Sains dan Teknologi (SENASAINS 1st)

Universitas Muhammadiyah Sidoarjo

form penilaian yang dilakukan oleh Dosen manufaktur. Plat yang telah selesai dilas diberikan cairan penetrant. Cairan penetrant digunakan untuk melihat apakah terdapat crack pada hasil las.

Tabel 3. Kriteria Hasil Las

\begin{tabular}{cll}
\hline No & \multicolumn{1}{c}{ Kriteria Hasil Las } & Cacat Las \\
\hline 1 & $0 \mathrm{~mm}^{2}$ (tidak ada retak) & Retak \\
\hline 2 & $\begin{array}{l}\text { Tidak lebih dari dua buah terak dengan luas } 2 \mathrm{~mm}^{2} \text { untuk panjang } \\
\text { pengelasan } 200 \mathrm{~mm}\end{array}$ & Terak terperangkap \\
\hline 3 & Tidak ada lubang pada akhir jalur las & Lubang pada akhir jalur las \\
\hline 4 & $\begin{array}{l}\text { Lebar jalur las pada sambungan tumpul tidak boleh lebih dari } 3 \mathrm{~mm} \text { dari } \\
\text { pinggir kampuh las }\end{array}$ & Jalur las terlalu lebar \\
\hline 5 & Tidak ada keropos/ porositas pada logam las & Keropos \\
\hline 6 & Percikan las tidak boleh berlebihan dan bisa dibersihkan & Over spatter \\
\hline 7 & Lubang pada permukaan dengan kedalaman $\leq 3 \mathrm{~mm}$ dan diameter $\leq 1 \mathrm{~mm}$ & Pin hole \\
\hline
\end{tabular}

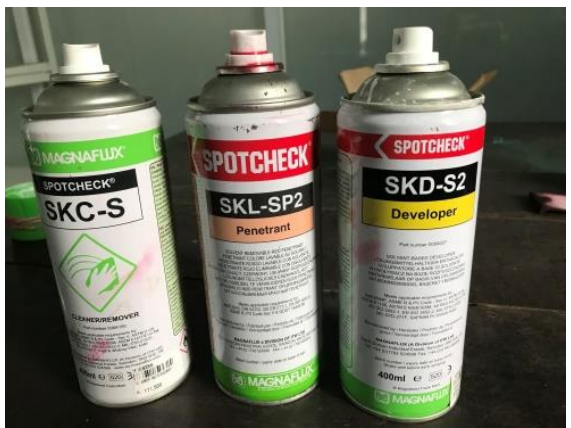

Gambar 1. Spotcheck (Penetrant)

\section{HASIL DAN PEMBAHASAN}

Hasil dari perhitungan ANOVA untuk control factors digunakan untuk mengetahui faktor apa yang paling berpengaruh pada kualitas hasil las. Metode Taguchi mengimplementasikan pooling-up factors untuk menghindari kontirbusi dari faktor yang tidak signifikan. Pooling-up factors adalah metode untuk mengurangi nilai error perbedaan faktor yang signifikan dan tidak signifikan [12]. Penilaian hasil las diberikan pada Tabel 4 berikut. Serta, hasil perhitungan ANOVA diberikan pada Tabel 6.

Tabel 4. Hasil Penilaian Las

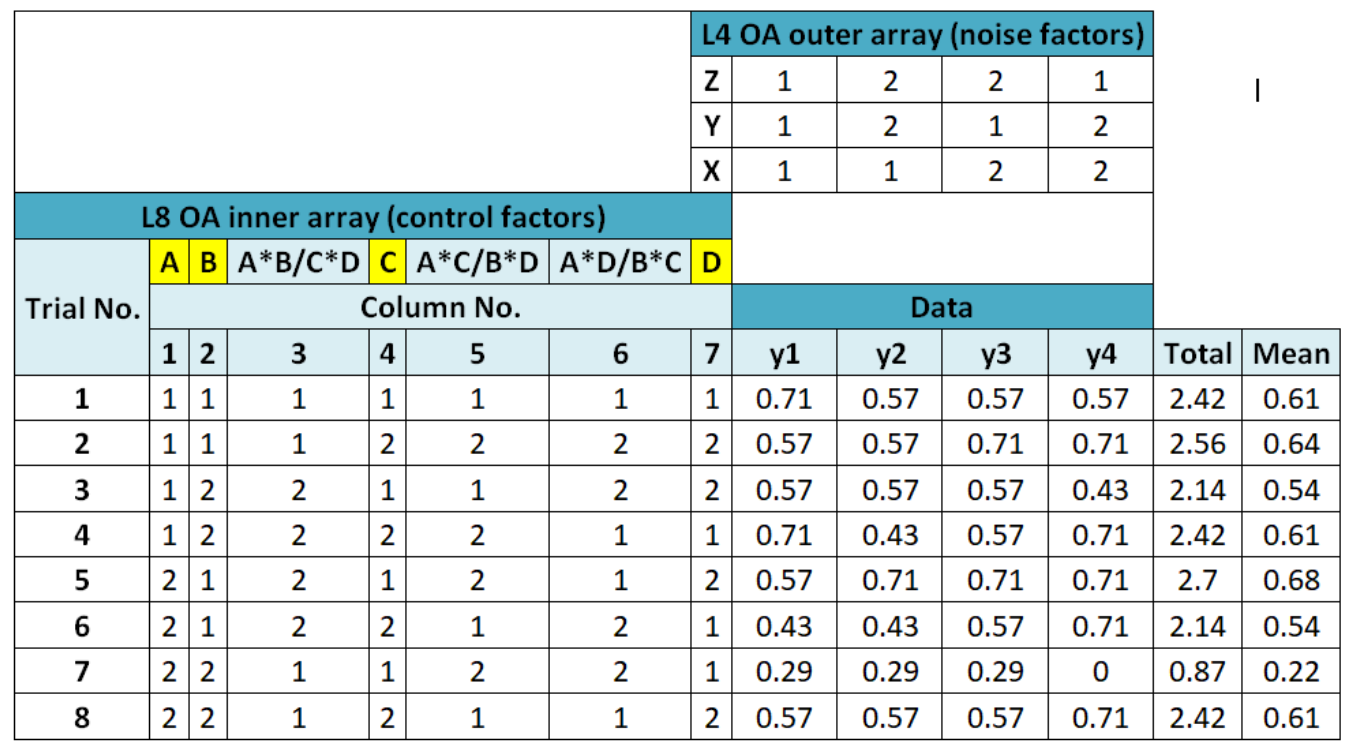


Tabel 6. Hasil Perhitungan ANOVA

\begin{tabular}{llllll}
\hline Source & SS & $\mathbf{v}$ & $\mathbf{V}$ & $\mathbf{F}$ & $\mathbf{P}$ \\
& & & & & \\
\hline $\mathrm{A}$ & 0.06 & 1 & 0.06 & 5.98 & \\
\hline $\mathrm{B}$ & 0.12 & 1 & 0.12 & 11.68 & \\
\hline $\mathrm{E}$ & 0.04 & 1 & 0.04 & 3.84 & 4.84 \\
\hline $\mathrm{C}$ & 0.06 & 1 & 0.06 & 5.98 & 7.54 \\
\hline $\mathrm{A} \times \mathrm{C}$ & 0.01 & 1 & 0.01 & 0.98 & 1.23 \\
\hline $\mathrm{A} \times \mathrm{D}$ & 0.16 & 1 & 0.16 & 15.23 & 19.19 \\
\hline $\mathrm{D}$ & 0.12 & 1 & 0.12 & 11.68 & 14.71 \\
\hline $\mathrm{e}$ & 0.25 & 24 & 0.01 & & 1.26 \\
\hline $\mathrm{T}$ & 0.82 & 31 & & & 100 \\
\hline
\end{tabular}

Tabel 7. Hasil ANOVA dengan MS. Excel

\begin{tabular}{|c|c|c|c|c|c|c|}
\hline ANOVA & & & & & & \\
\hline Source of Variation & $S S$ & $d f$ & $M S$ & $F$ & P-value & F crit \\
\hline Rows & 0.57507 & 7 & 0.08215 & 7.34398 & 0.00017 & 2.48758 \\
\hline Columns & 0.01436 & 3 & 0.00479 & 0.42788 & 0.73511 & 3.07247 \\
\hline Error & 0.23492 & 21 & 0.01119 & & & \\
\hline Total & 0.82435 & 31 & & & & \\
\hline
\end{tabular}

Selanjutnya, setelah dilakukan perhitungan ANOVA, dilakukan perhitungan mean effect factor. Mean effect factors digunakan untuk mengetahui pengaruh masing-masing faktor terhadap masing-masing respon. Kriteria penilaian yang digunakan pada penelitian adalah lower is better, dimana nilai yang rendah diartikan bahwa faktor tersebut tidak berpengaruh terhadap hasil las. Hasil perhitungan mean effect factor diberikan pada Tabel 8.

Tabel 8. Mean Effect (Control Factors)

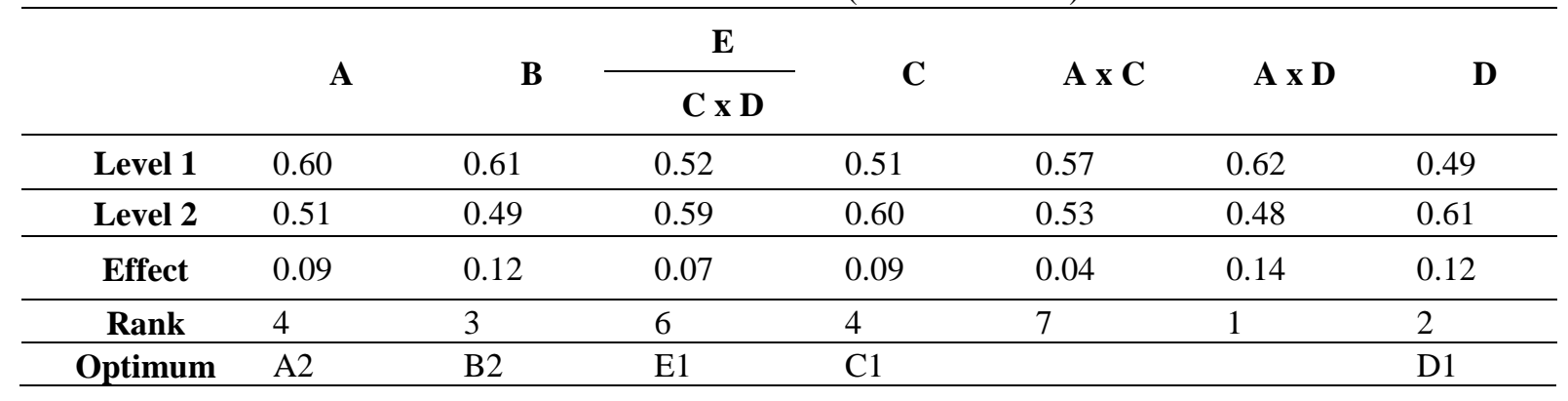

Berdasarkan pada hasil penilaian dengan menggunakan form kriteria cacat didapatkan hasil eksperimen trial no 7 merupakan hasil yang paling baik dengan deskripsi kombinasi level sebagai berikut:

1. Faktor $(\mathrm{A} \times \mathrm{D})^{2} \quad$ : Elektroda $\mathrm{x}$ Tebal Plat Level 2

2. Faktor $\mathrm{D}_{1}$ : Tebal Plat Level $1(4 \mathrm{~mm})$

3. Faktor $\mathrm{B}_{2}$ : Ampere Las Level 2 (20 Ampere)

4. Faktor $\mathrm{C}_{1}$ : Metode Pengelasan Level 1 (Spiral) 


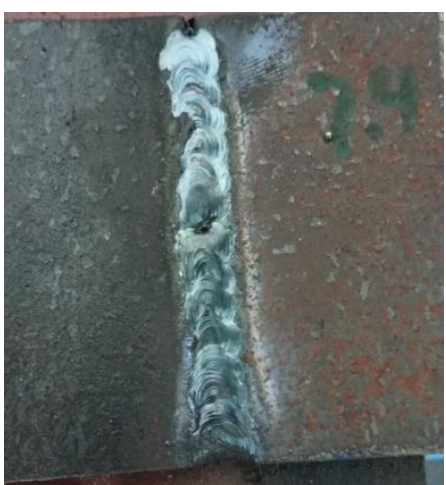

Gambar 2. Hasil Las Trial No 7 (Baik)

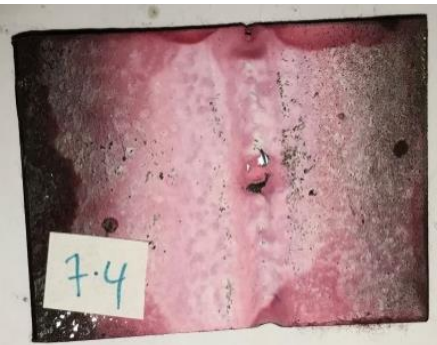

Gambar 3. Eksperimen Trial 7 dengan Spotcheck

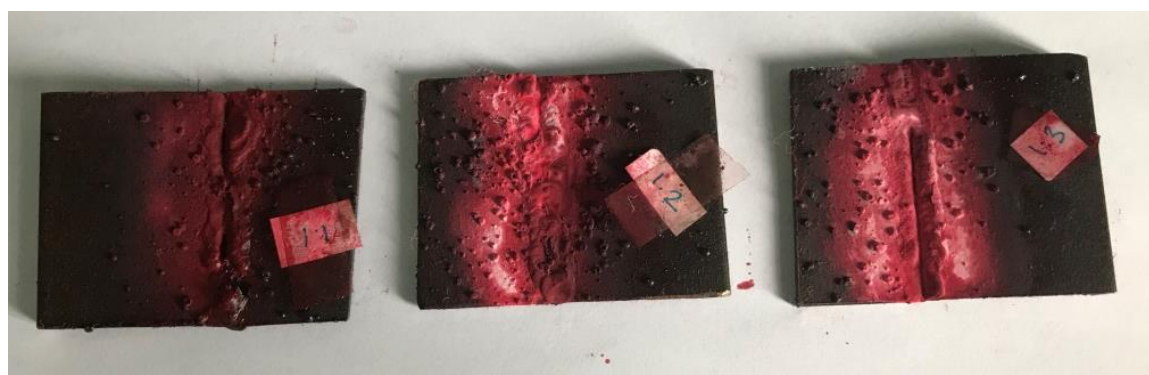

Gambar 4. Hasil Las Cacat

Adapun peringkat faktor yang mempengaruhi hasil atau kualitas las berdasarkan hasil perhitungan ANOVA yaitu:

1. Kombinasi faktor A x D : Elektroda x Tebal Plat

2. Faktor $\mathrm{D}_{1} \quad$ : Tebal plat level $1(4 \mathrm{~mm})$

3. Faktor $\mathrm{B}_{2} \quad$ : Ampere las level 2 (20)

4. Faktor $\mathrm{A}_{2} \quad$ : Elektroda level $2(\mathrm{RD}-460)$

5. Faktor $\mathrm{C}_{1} \quad$ : Metode pengelasan level 1 (spiral)

6. Faktor $\mathrm{E}_{1} \quad$ : Kecepatan pengelasan level 1 (cepat)

7. Kombinasi faktor A x C : Elektroda x Metode pengelasan

Selanjutnya, dengan menggunakan kombinasi faktor sesuai dengan nilai mean effect dapat dilakukan konfirmasi eksperimen untuk melihat apakah benar faktor-faktor tersebut dapat meningkatkan kualitas hasil las atau mengurangi cacat hasil las seminimal mungkin. Konfirmasi eksperimen dilakukan sebanyak 4 kali pengulangan. Hasil konfirmasi eksperimen didapatkan hasil las yang baik (tidak ada cacat). Hal ini membuktikan bahwa metode Design of Experiments dengan menggunkaan perhitungan ANOVA memberikan hasil yang sesuai (baik). Peneliti mengetahui faktor-faktor apa saja yang dapat mengoptimalkan kualitas hasil las. 

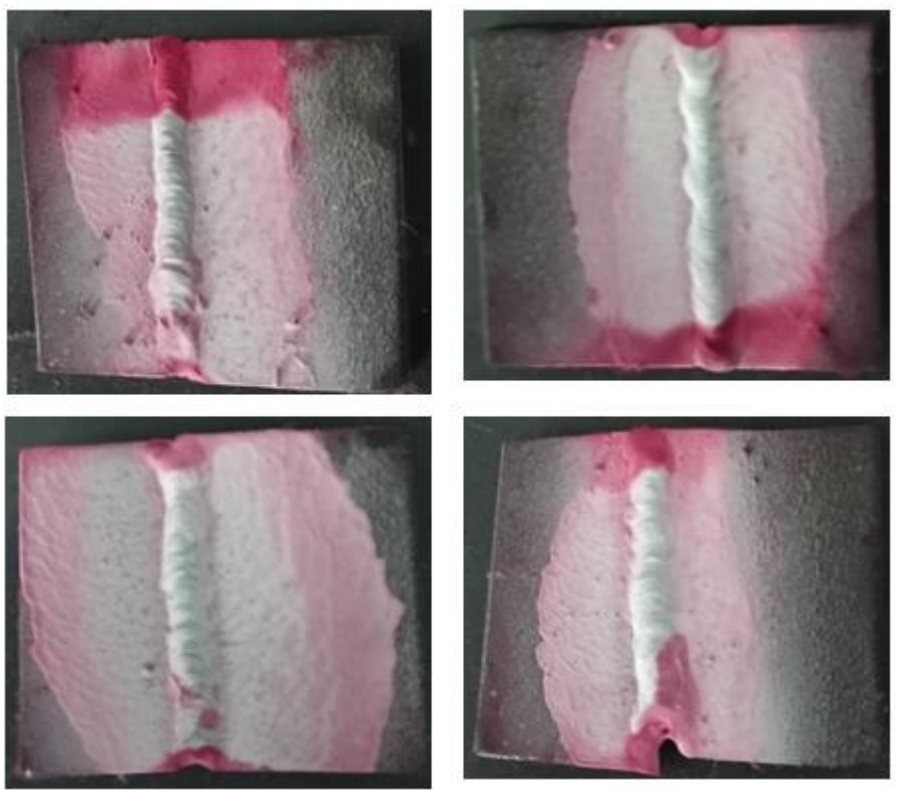

Gambar 5. Hasil Konfirmasi Eksperimen

\section{KESIMPULAN}

Hasil penilaian berdasarkan kriteria cacat las dan perhitungan ANOVA menunjukkan hasil yang sesuai. Berdasarkan penilaian hasil las dengan form kriteria cacat las, ekperimen trial 7 adalah hasil las terbaik dengan ratarata nilai 0.22. Nilai tersebut merupakan nilai terendah dan diartikan tidak ada cacat hasil las. Sedangkan, hasil dengan cacat las terbanyak yaitu pada trial no 2 dengan rata-rata nilai 0.64. Cacat las tersebut yaitu terdapat lubang, keropos, over spatter, dan pin hole, bahkan terdapat benda kerja yang tidak menyambung (crack). Hasil las dengan kualitas yang baik sesuai dengan kombinasi faktor yang baik dan sesuai dengan hasil perhitungan ANOVA dan mean effect factor. Faktor yang mempengaruhi kualitas hasil las secara berurut yaitu tebal plat, ampere las, elektroda, dan metode pengelasan. Sedangkan, faktor kecepatan pengelasan merupakan faktor yang secara sognifikan tidak mempengaruhi kualitas las.

\section{UCAPAN TERIMA KASIH}

Terimakasih penulis ucapkan kepada tim peneliti yang telah bekerja dengan sangat baik, sehingga penelitian ini berjalan dengan baik. Serta, terimakasih kepada seluruh tim pendukung yang selalu mendukung kegiatan penelitian untuk lebih baik.

\section{REFERENSI}

[1] O. D. Nata et al., "ANALISIS KEKUATAN UJI BENDING PENGELASAN SHIELDED METAL ARC WELDING ( SMAW ) MATERIAL SS400 MENGGUNAKAN KAWAT LAS E6013 BERBAGAI VARIASI ARUS LISTRIK," vol. 2, pp. 12-15, 2021.

[2] A. Sorgdrager, R. J. Wang, and A. Grobler, "Taguchi method in electrical machine design," SAIEE Africa Res. $J$. , vol. 108, no. 4, pp. 150-164, 2017, doi: 10.23919/saiee.2017.8531928.

[3] M. Z. Mawahib, S. Jokosisworo, and H. Yudo, "Pengujian Tarik Dan Impak Pada Pengerjaan Pengelasan SMAW Dengan Mesin Genset Menggunakan Diameter Elektroda Yang Berbeda," Kapal J. Ilmu Pengetah. dan Teknol. Kelaut., vol. 14, no. 1, pp. 26-32, 2017, doi: 10.14710/kpl.v14i1.15533.

[4] F. Azharul, A. Dharmanto, and Wilarso, "TRAKSI: Majalah Ilmiah Teknik Mesin," TRAKSI Maj. Ilm. Tek. Mesin, vol. 20, no. 1, pp. 45-58, 2020.

[5] D. R. Prajapati and D. V. S. Cheema, "Optimization of Weld Crack Expansion Defect of Wheel Rims by Using Taguchi Approach: A Case Study,” Optimization, vol. 2, no. 8, pp. 3437-3446, 2013, [Online]. Available: http://citeseerx.ist.psu.edu/viewdoc/download?doi=10.1.1.1056.4721\&rep=rep1\&type=pdf.

[6] A. S. Nurrohkayati, A. S. Nurrohkayati, and . B., "Identify the Influence of Ingredients and Cake Baking for Cupcake using Design of Experiments," Int. J. Eng. Technol., vol. 8, no. 1.1, pp. 104-110, 2019, [Online]. Available: https://www.sciencepubco.com/index.php/ijet/article/view/24787.

[7] A. S. Nurrohkayati and M. Khairul, "Identifikasi pengaruh takaran bahan dasar terhadap kualitas mie basah berdasarkan daya serap air dan metode doe," vol. 6, no. 1, pp. 143-149, 2020. 
[8] M. I. Qazi and R. Akhtar, "Strength of Shielded Metal Arc Welding ( SMAW ) Process for," pp. 97-103, 2019.

[9] S. Rao, P. Samant, A. Kadampatta, and R. Shenoy, “An Overview of Taguchi Method: Evolution, Concept and Interdisciplinary Applications," Int. J. Sci. Eng. Res., vol. 4, no. 10, pp. 621-626, 2013.

[10] I. Basori, "Analisa Kekuatan Tarik Baja Konstruksi Bj 44 Pada Proses Pengelasan SMAW dengan Variasi Arus Pengelasan," J. Konversi Energi dan Manufaktur UNJ, vol. Edisi terb, no. April, pp. 72-76, 2014.

[11] W. S. Nugroho, "Buku informasi memperbaiki hasil pengelasan c.24las01.026.01," pp. 1-67, 2018.

[12] A. Siti, Binyamin, M. Khairul, A. S. Nurrohkayati, and . B., "Identify the Effect of the Different Ingredients for Wet Noodles Based on Water Absorption Using Design of Experiment," Int. J. Eng. Technol., vol. 9, no. 2, pp. 143-149, 2020, doi: 10.11648/j.ajsea.20200902.11. 